\author{
REGINA HERNÁNDEZ FRANYUTI \\ INSTITUTO DR. JOSÉ MARÍA LUIS MORA
}

\title{
Un espacio entre la religión y la diversión: el Paseo de las Cadenas (I840-1860)
}

Toda la ciudad existente, toda la ciudad heredada, es toda ella ciudad histórica.

Jordi Borja

$\mathrm{E}$ L Zócalo, Plaza Mayor, Plaza de Armas o Plaza de la Constitución, se yergue majestuoso en la ciudad de México. Sitio de llegada, paso obligatorio para miles de transeúntes, ha sido en el presente y en el pasado una geometría, una figura y una presencia que evoca, en uno y otro tiempo, las responsabilidades colectivas de unos hacia otros.

Como parte fundamental de la estructura urbana ha sido escenario donde se concentran las actividades cívicas, religiosas, recreativas y comerciales. Núcleo de la vida comunitaria, foro donde los habitantes llevan a cabo sus rituales día a día, así como sus ceremonias extraordinarias. Pulso de lo cotidiano, estructura que absorbe y centraliza la vida urbana, símbolo y rostro de la ciudad. ${ }^{\mathrm{I}}$ Espacio versátil que se comparte, y donde las relaciones personales y los diversos grupos sociales se comunican, actúan y se congregan. Es un origen y un destino. Un espacio colectivo donde las calles, banquetas y edificios que la limitan fungen como elementos integradores entre lo público y lo privado.

I. Miguel Rojas-Mix, La Plaza Mayor, Barcelona, Muchnik Editores, 1978, p. II4. 
IO2

REGINA HERNÁNDEZ FRANYUTI

Esta plaza genera espacios residuales entre ella y los edificios que la circundan, son espacios públicos potenciales cuyo uso colectivo y apropiación progresiva de la gente los convierte en lugar de encuentro, en sitio de expresión colectiva y de diversidad social y cultural. Son espacios de transición que le van a permitir al individuo recuperar su ser social. ${ }^{2}$

En la historia de la Plaza Mayor de la ciudad de México, el Paseo de las Cadenas es el ejemplo representativo de cómo el espacio residual entre la plaza y el atrio de la catedral se convirtió en un espacio de uso colectivo donde se materializaron las relaciones entre los habitantes de la ciudad, el poder civil y el religioso. Conocer la historia de este espacio público permitirá entender la historia de la capital.

\section{Un nuevo paseo}

Desde la época novohispana no existía una diferencia entre la Plaza Mayor y el atrio de la catedral. Ambos mantenían una versatilidad de funciones que permitían no sólo las relaciones cotidianas sino que también se utilizaban como receptáculo para la exteriorización del culto, para la proyección del sentimiento religioso a través de imágenes, catequesis, fiestas y procesiones. Lo público servía a lo privado y lo privado se volvía público cuando las manifestaciones religiosas salían a la plaza y a las calles. Hacia finales del siglo xvıII, cuando la racionalidad se imponía a través de una serie de reformas urbanas, la separación entre la Plaza Mayor y el atrio, entre lo público y lo privado se reclamaba como necesaria. En I794, el virrey segundo conde Revillagigedo propuso construir un enrejado para separar y definir ambos espacios. Esta obra no pudo llevarse a cabo entonces para diferenciar lo público y lo privado; el cabildo catedralicio mandó poner I24 postes de dos varas de alto que se situaron a distancias proporcionadas y unidos entre sí por 125 cadenas de hierro, obra que se terminó en 1797.

El espacio entre la plaza y las cadenas era un espacio abierto que fue adquiriendo un uso diferente. Las personas que salían de los servicios religiosos le dieron una actividad momentánea, que tenía que ver con lo familiar, con el encuentro o el desencuentro. El uso diario lo dotó de la consideración de un paseo o espacio público porque allí se congregaba un grupo de gente, se pro-

2. Anthony Vidler, "Los escenarios de la calle: transformaciones del ideal y de la realidad" en Stanford Anderson (ed.), Calles, problemas de estructura y diseño, versión castellana de Eduardo Mira, Cristina Hola y Goncal Zaragoza, Barcelona, Gustavo Gili, I98I, p. 58. 


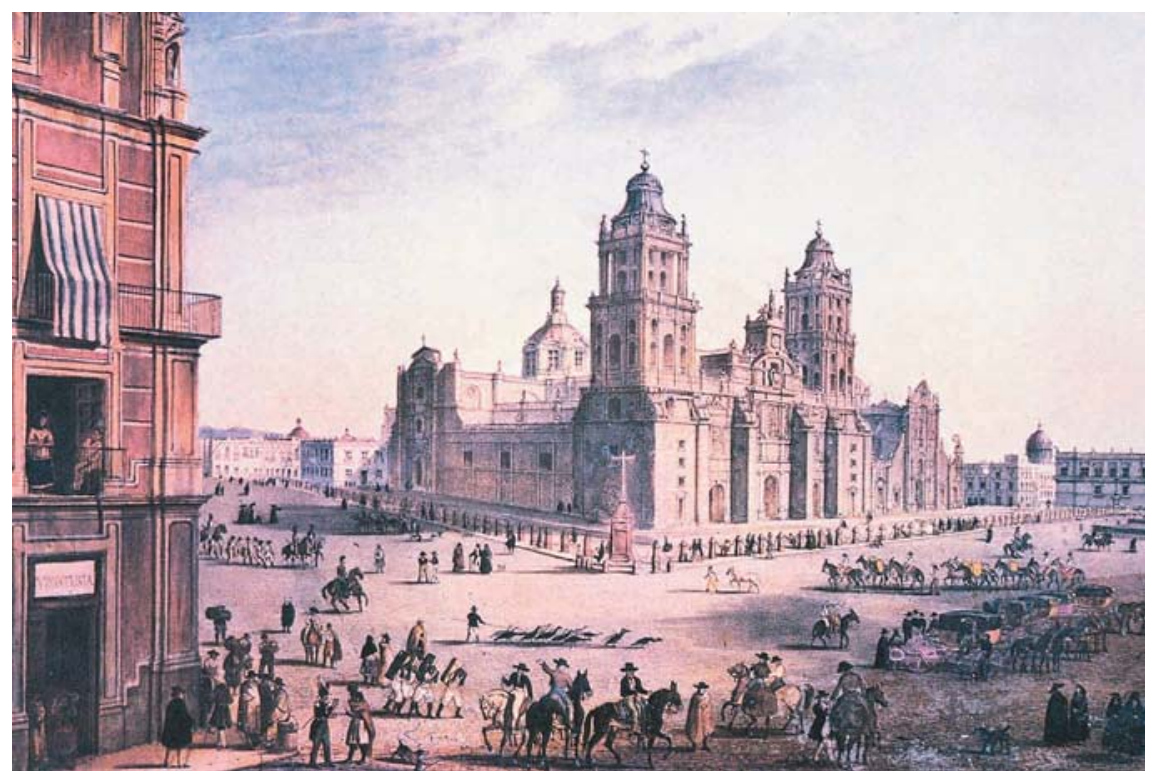

I. Carl Nebel, La Plaza Mayor de México. I829-1834, tomada de Carl Nebel, Viaje pintoresco y arqueológico sobre la parte más interesante de la República mexicana en los años transcurridos desde I829 hasta I834, México, Manuel Porrúa, I963, p. 3I, lám. 4.

movían los encuentros sociales, el ritual y la interacción, era gratuito y permitía la libertad de acción. ${ }^{3}$ Así, lo registró Carl Nebel entre i829 y I834 con las cadenas limitando un espacio que aún no adquiría la distinción de un paseo público (fig. I).

Una vez terminados los oficios religiosos, las personas lo comenzaron a usar para reunirse o platicar, los vendedores ambulantes se situaron en él y las cadenas se convirtieron en asientos de aquellos o aquellas que hacían un alto en su cotidianidad para disfrutar el paso de las personas. "El sol de la mañana apenas permitía estar un rato en las cadenas, damas y caballeros se refugiaban en el Portal de Mercaderes, en donde verdaderamente venía a verificarse el paseo iniciado desde las puertas del templo". ${ }^{4}$

3. Spiro Kostof, The City Assembled. The Elements of Urban from through History, Boston, Bulfinch Press Book Little, Brown and Company, I992, p. I23.

4. José María Marroquí, La ciudad de México, México, Ediciones La Europea, I900, t. I, p. 277. 
IO4

REGINA HERNÁNDEZ FRANYUTI

Entre 1840 y I860 esta misma escena se repetía en las noches de los días festivos o bien en las noches de luna clara. Poco a poco estas 150 varas de largo y seis de ancho se fueron convirtiendo en un paseo cotidiano para los habitantes de la ciudad. No era un paseo como lo demandaban los cánones, es decir, espacios arbolados, recreativos, planeados de antemano para ser recorridos a pie, a caballo o en carruaje, que buscaban poner en contacto a los paseantes con la naturaleza como lo hacían la Alameda, el Paseo de Bucareli, el de Revillagigedo, La Viga y más tarde el Paseo de Azanza. Era un paseo creado espontáneamente por los propios habitantes de la ciudad, estaba cerca de su hacer cotidiano y esa costumbre lo había dotado de un uso para el público que lo demandaba.

No tenía grandes comodidades, la gente se movía entre empujones y apretones, entre mendigos y vendedores ambulantes; caminaba levantando un constante e inclemente polvo, formando dos largas y desordenadas filas, una para ir y otra para venir. Su espontaneidad no registra el momento exacto de su inicio, pero es su uso constante el que lo dota de presencia.

Así, considerando que este pequeño espacio formaba parte de la plaza, la cual era propiedad del ayuntamiento, éste, a través de su presidente José María Mejía, decidió, en I840, llevar a cabo la plantación de fresnos en la orilla de la angosta banqueta que circundaba el atrio de la catedral para brindar comodidad a los habitantes de la ciudad. El uso colectivo le concedió nombre y se empezó a conocer como el Paseo de las Cadenas. Pequeño espacio que permitía el disfrute y la convivencia. Era un oasis, un refugio para aquellos que sentían la necesidad de convivir más allá de los espacios privados o cerrados. Día con día, noche tras noche, fiesta tras fiesta, procesión tras procesión, el Paseo de las Cadenas se fue distinguiendo como un espacio propio de la ciudad.

En I847 —después del terrible golpe de la invasión norteamericana- el ayuntamiento autorizó ampliar la banqueta, colocar asientos de mampostería y rodear a los fresnos con arriates de madera. Dos años después, se colocaron faroles con lámparas de trementina. La presencia de árboles y asientos produjo que en las mañanas se mitigara el sol y se pudiera disfrutar de un paseo delicioso:

[...] la belleza de las mexicanas, su natural gracia, la elegancia de sus trajes, el crecido número de escogidos concurrentes, la agradable conversación, eran sobrados estímulos para que la concurrencia aumentase de domingo a domingo y para que acabase, como acabó, el paseo del portal. ${ }^{5}$ 


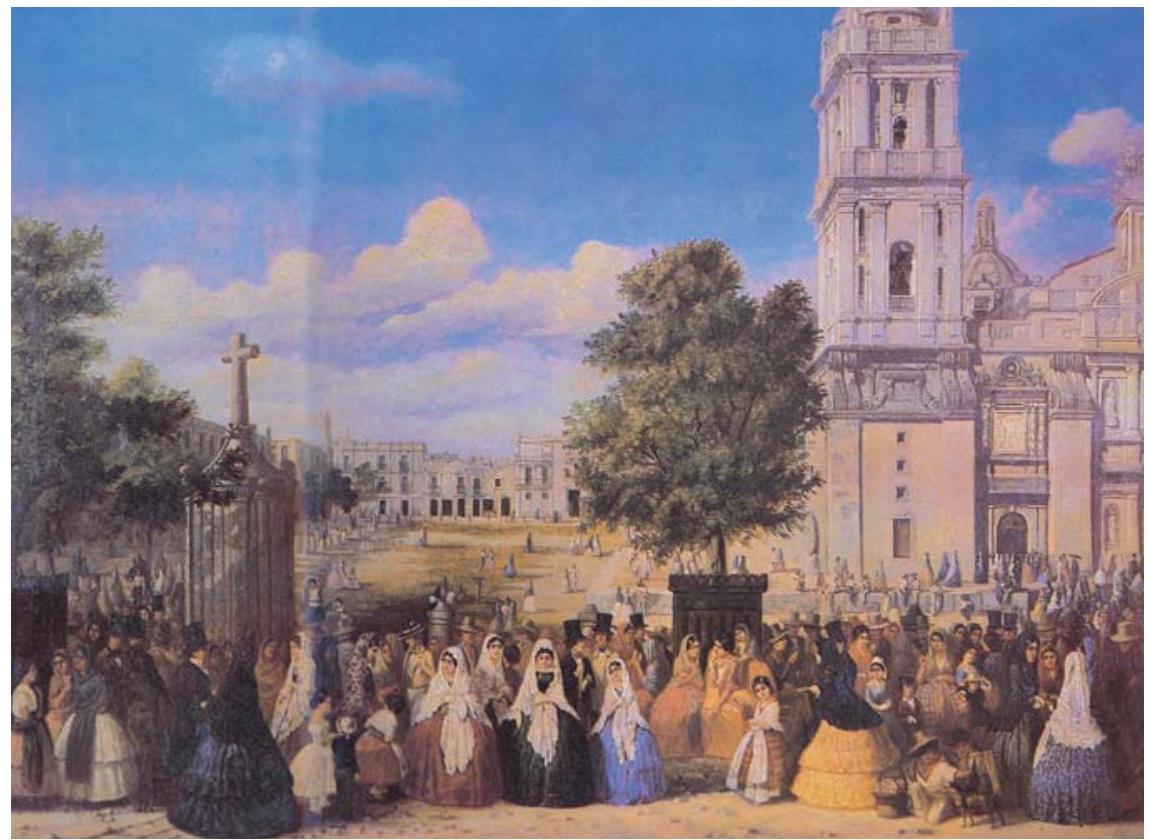

2. J.S. Hegi, La Catedral y el Paseo de las Cadenas el Jueves Santo, I854, tomada de Mario de la Torre (ed.), Hegi. La vida en la Ciudad de México, México, Bancreser, 1989, p. 7.

Dos hechos contribuyeron a que el Paseo de las Cadenas aumentara su preferencia en el gusto de los habitantes de la ciudad: el uso del alumbrado público y la existencia de cuerpos de vigilancia como la policía nocturna, ambos permitieron la utilización de los espacios urbanos como escenarios para la distracción y el aprovechamiento del tiempo libre. Así, se incrementó la asistencia a las tertulias, teatros, cafés, fondas, tabernas, etc.

Durante dos décadas, de I840 a I860, el Paseo de las Cadenas fue el lugar donde se llevaba a cabo la sociabilidad informal, la interacción de los diferentes grupos y clases sociales. Fuera por las mañanas o aprovechando la claridad de las noches de luna y la débil luz que provenía de los faroles, por el Paseo de las Cadenas desfilaba una población que buscaba desde el sustento diario con la venta de diversos productos hasta la que concurría para divertirse, pasearse, enamorarse o simplemente cenar. En I854 J. S Hegi pintó un óleo donde se puede ver la interacción de los grupos sociales en este paseo (fig. 2). 
[En las noches de] luna clara y llena, que en un cielo raso de un azul delicado envía sus destellos insinuantes y voluptuosos. Algunos grupos de jóvenes, vestidas de ligeros trajes blancos, dirigen sus ojos hacia el disco pálido, [...] Cualquiera que las ve de lejos y con fantasía de poeta, creería que eran bellas ninfas, [...] Otras se mecen con graciosa coquetería [...] Varias se agrupan en las gradas de las altas cruces que se alzan en los ángulos [...] Entretanto gira, circula, se roza, se mezcla, se pierde una inmensa serpiente animada, en que cada anillo es un ser viviente, y en ese estrecho y largo pasadizo, allí, son las miradas furtivas y de inteligencia entre los amantes [...] Allí se escuchan palabras misteriosas [...] Unos hablan de política; otros formulan sus proyectos comerciales; estos dicen la crónica social; aquellos deliran sobre ciencia y poesía. ${ }^{6}$

Era además, según García Cubas,

[...] el lugar de las citas amorosas, en donde el travieso hijo de Venus, (Cupido) ligero e inconstante como una mariposa, vuela en giro oblicuo, entre los ramajes de los fresnos de la calzada, y si llega a posarse en alguno de éstos, es para ocultarse y herir desde lejos, con certero dardo y a mansalva a sus descuidadas víctimas. ${ }^{7}$

Jóvenes y adultos escogían las noches de luna para incrementar sus conquistas amorosas, novios o amantes recurrían al lenguaje de las señas para traspasar la vigilancia certera del padre, de la madre, del marido o de la esposa:

Allí está apoyado en el poste, frente a nosotros un jovencito boquirrubio que, de vez en cuando, hace señales telegráficas con el puro encendido a esa joven, casi una niña, que tiene delante. Por nuestra izquierda vienen dos lindas jóvenes, llenando la calzada con sus vestidos de excesiva anchura, según la moda. Una de ellas no cesa de mirar hacia atrás y es que sin duda la sigue el novio. ¡Cómo lucen sus hermosos vestidos a la luz de la luna!, los que podemos admirar en virtud de la poca gente que en este momento pasa; una lleva su traje color de rosa con tres olanes guarnecidos de listón y fleco; las dos ostentan ricas manteletas y sombreros de paja, a la moda. Mira

6. Marcos Arróniz, Manual del viajero en México, edición facsimilar, México, Instituto Mora, I991, p. I62.

7. Antonio García Cubas, El libro de mis recuerdos, México, Editorial Patria, 1960, p. 2 I4. 
con qué donaire la enamorada saca por debajo de la manteleta la mano y entrega al novio una carta. ${ }^{8}$

Pero no sólo transitaba la aristocracia, sino que también se encontraba una diversa gama de vendedores ambulantes: el vendedor de castañas asadas o cocidas, el de turrones de almendra enteras o molidas, la vendedora de patos o de juiles, el vendedor de juguetes, el cantante, la tamalera que situada en una esquina ofrecía sus tamales de chile, dulce y de manteca. El pastelero quien ponía sobre una mesa un artefacto para mantener calientes los pasteles, que consistía en un tripié de fierro que sostenía un aro de barril sobre el cual descansaba de costado una olla grande de barro, que contenía en su interior los pasteles; por encima de la olla se ponían rajas de ocote ardiendo. El pastelero atraía a los compradores entonando constantemente una pícara canción.

Mi vecina de allí enfrente

Se llamaba doña Clara;

Y si no se hubiera muerto,

Todavía así se llamara.

A cenar pastelitos y crispana, pasen rotos a cenar

Las mujeres al querer

Son como el indio a comprar

Aunque nos despachen bien

No cesan de regatear

A cenar pastelitos y crispana, pasen rotos a cenar

El pobre que se enamora

De mujer que tiene dueño,

Queda como el mal ladrón

Crucificado y sin dueño. ${ }^{9}$

La vida del paseo fue captada por Casimiro Castro en su litografía Las cadenas en noche de luna, realizada en 1855 (fig. 3).

8. García Cubas, op. cit., p. 219.

9. Ibidem, p. 220. 
IO8 REGINA HERNÁNDEZ FRANYUTI

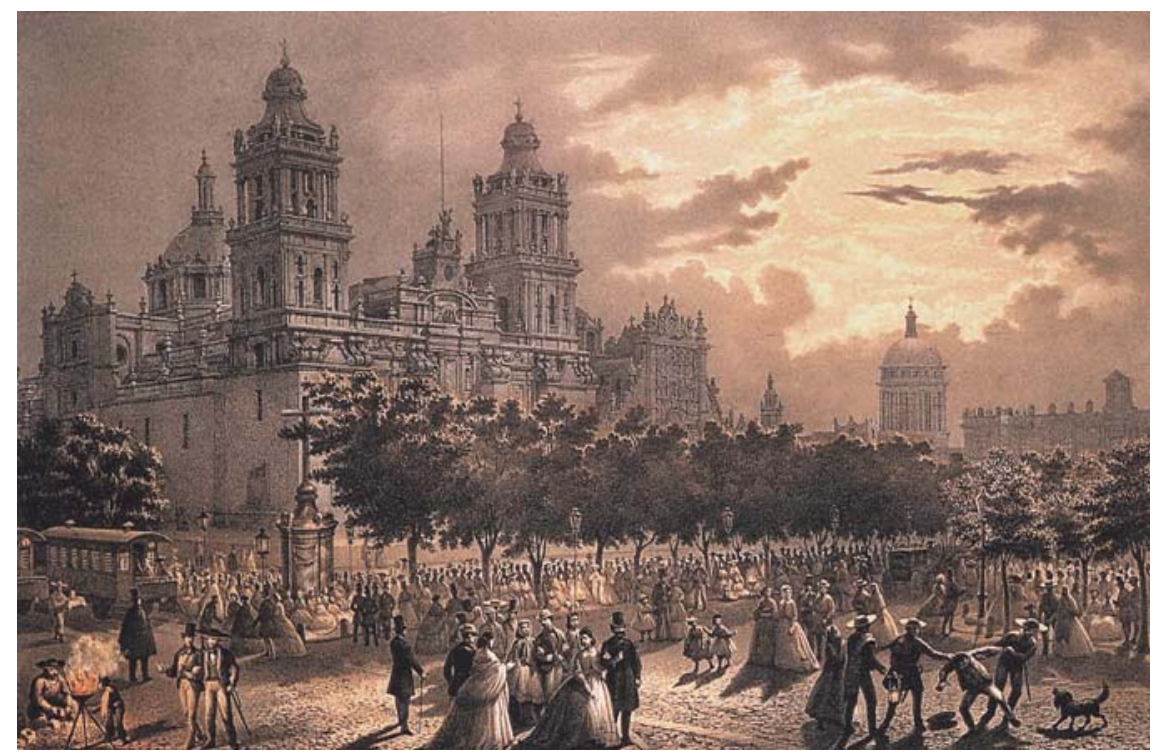

3. Casimiro Castro, El Paseo de las Cadenas en noche de luna, I855, tomada de Carlos Monsiváis et al., Casimiro Castro y su taller, México, Instituto Mexiquense de Cultura/Fomento Cultural Banamex, 1996, p. I34.

\section{El Paseo y la ciudad}

El Paseo de las Cadenas se fue integrando a la cotidianidad de los habitantes de la ciudad. Para la segunda mitad del siglo xIx, la ciudad de México estaba dividida en ocho cuarteles mayores y 32 menores, rodeada por las garitas de: Peralvillo, San Lázaro, La Viga, La Candelaria, Belén, y San Cosme. Sus aproximadamente 200 mil habitantes se distribuían en 316 calles, I40 callejones, I2 puentes, 90 plazas y plazuelas y I2 barrios. La ciudad era un mosaico de variados grupos sociales. Existían en la ciudad 4IO abogados, I4 arquitectos, I4 agrimensores, 847 aguadores, 94 billeteros, I600 cargadores, IOOI criados, 425 I criadas, 20 médicos cirujanos, siete parteras conocidas como tales, 34 farmacéuticos, 43 escribanos, siete dentistas, I5 evangelistas, siete ingenieros civiles con título, 25 voceadores, 69 repartidores de impresos, ${ }^{10}$ así como un sinfín de mendigos y vendedores ambulantes que, procedentes de los pueblos de los alrededores, recorrían las calles y plazas anunciando a viva voz sus mercancías. 


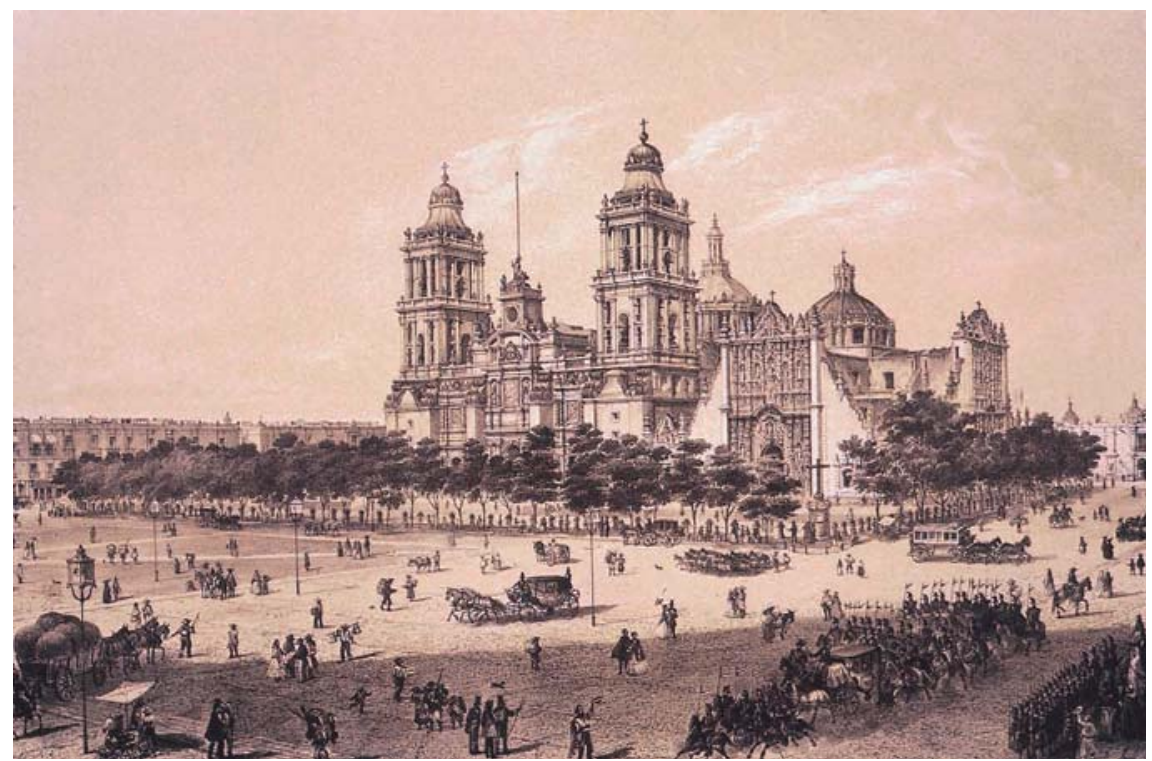

4. Casimiro Castro, La Catedral de México, tomada de Carlos Monsiváis et al., Casimiro Castro y su taller, México, Instituto Mexiquense de Cultura/Fomento Cultural Banamex, 1996, p. I46.

Esta ciudad, declarada en I824 como capital federal, sede de los poderes federales, se había convertido en el teatro donde se realizaban motines, desfiles de triunfadores, cambios de mando y celebraciones de triunfo. Era el escenario a donde llegaban y en donde terminaban los levantamientos y las asonadas. Era el centro nuclear de las diferentes actividades y por lo tanto se había convertido en un codiciado botín político. Pero además, era una ciudad de contraste.

Los grandes contrastes sociales se reflejaban día con día en el Paseo de las Cadenas. Allí los citadinos hablaban o discutían sobre la inestabilidad política, unos a otros se distinguían como liberales o conservadores, los primeros se congratularon por el triunfo de la revolución de Ayutla, y los segundos se agruparon bajo el estandarte de la religión católica, pero ninguno de ellos dejó de gozar de un rato de esparcimiento en el Paseo, disfrutando de "lo bello del lugar, lo interesante de la concurrencia, y la variedad de lances, dignos de observación” (fig. 4). ${ }^{\text {II }}$

II. Manuel Orozco y Berra, La ciudad de México, Ernesto de la Torre Villar (pról.), México, Porrúa (Colección Sepan cuántos, núm. 520), 1987, p. 283. 
En las calles, cafés, plazas, mercados, comercios y tertulias el tema de discusión invariablemente era político. La ciudad veía cómo día a día las propuestas liberales ponían en jaque al poder monopólico de la Iglesia y rompían con la vieja alianza establecida por siglos, entre la Iglesia y el Estado. Liberales y conservadores se enfrascaron en una lucha, en la cual los liberales buscaban romper la política monopólica de las corporaciones para establecer los fundamentos de un Estado moderno y los conservadores promovían las ideas de conservar y recuperar el control del Estado limitando las acciones de la política federal. El triunfo liberal de i855 fue el inicio de una política que pondría fin al viejo sistema corporativo. El punto central sería limitar el control de la Iglesia.

La Iglesia — según la Noticia de las fincas pertenecientes a corporaciones civiles y eclesiásticas del Distrito de México - tenía en la ciudad de México inmuebles por valor de 16,584,960 pesos, siendo la más rica la Archicofradía del Santísimo en catedral que contaba con fincas con un valor de 320,828 pesos. La ley Lerdo había desamortizado y puesto en venta estos bienes. La ciudad veía asombrada cómo se cerraban y tiraban templos y conventos. Nuevas calles se abrieron a través de capillas, claustros, conventos y huertas. La ciudad se dividía en los púlpitos, los sacerdotes exaltados defendían sus propiedades y los liberales justificaban las necesidades económicas de las reformas. Esta situación se reflejaría en un hecho tan simple que pretendía el beneficio del Paseo de las Cadenas.

\section{La solicitud para el mejoramiento del Paseo}

En este clima de efervescencia política, el I7 de enero de I857, el deán del cabildo de la Catedral metropolitana, el bachiller don Joaquín Mejía de Zaragoza, quien todavía no asimilaba la pérdida de los bienes de la Catedral, encontró entre su correspondencia una carta del secretario del ayuntamiento en la que le comunicaba, con mucho respeto, que el ayuntamiento de la ciudad en busca del "bien público" había acordado "la plantación de árboles en algunos parajes de esta Capital, a fin de que sirviendo al ornato y hermosura contribuya a la salubridad". ${ }^{12}$ Uno de esos lugares era sin duda el Paseo de las Cadenas, considerado como el sitio más indicado para ello, pues se beneficiaría también el atrio de la

I2. Archivo Histórico del Gobierno del Distrito Federal (AHGDF), Ayuntamiento, Arboledas, Sembradío de árboles en el atrio de la Catedral, I857, vol. 368, exp. 3. 
santa iglesia catedral. El interés del ayuntamiento era el "bien público" y éste también debería de ser el de las autoridades eclesiásticas.

Si el Ayuntamiento no estuviera tan convencido de que Vuestra Ilustrísima abunda, como él, en sentimientos benignos para cooperar al bien público y al ornato de la ciudad, no se hubiera dirigido a Vuestra Santa Iglesia, para que permitiéndole comenzar la plantación en el interior del atrio, le diga al mismo tiempo, si puede contribuir con algunas cantidades para llevar a cabo una mejora de tanta utilidad para la capital de la república, y que tanto va a contribuir a la hermosura del atrio, haciendo resaltar la magnificencia del templo. Espera pues, el Excelentísimo Ayuntamiento de ese venerable Cabildo la cooperación que lleva indicada, ofreciéndole por mi conducto las protestas de su distinguida consideración y respeto. Dios lo Guarde. ${ }^{\mathrm{I3}}$

Podemos imaginar la cara de asombro del bachiller Mejía. Imaginémoslo, molesto, sofocado, informando a las altas autoridades eclesiásticas que el ayuntamiento pretendía arreglar el Paseo de las Cadenas y que ellos pagaran las obras. El momento que se vivía en la relación Estado-Iglesia sembraba la duda y el temor pues podría significar la pérdida o expropiación del espacio.

Y cabría preguntarnos ipor qué la Iglesia dudaba de que las intenciones del ayuntamiento eran las de mejorar el Paseo de las Cadenas como una medida de higiene y de embellecimiento?

\section{La secularización de los espacios o la imagen del poder}

Desde las últimas décadas del siglo XviII la ideología ilustrada había promovido que los espacios públicos, de acuerdo con los intereses y con las necesidades de grupos urbanos en el ejercicio de sus capacidades de "poder" y de "poseer", se fueran transformando, por los usos que le diera la colectividad, en símbolos que representaban tanto las actitudes cotidianas, las formas de organización social como la ideología del grupo en el poder. En este sentido, podemos explicar que la solicitud del ayuntamiento buscaba modernizar un espacio que se consideraba público y necesario para el esparcimiento, la higiene de la ciudad y la salud de sus habitantes. Pero, si llevamos nuestro análisis más a fondo pode- 
mos señalar que acorde con la ideología del grupo en el poder, este espacio se convertiría en el medio que expresaba los intereses del gobierno en separar y romper el poder corporativo de la Iglesia, en secularizar la propiedad del suelo y la imagen urbana. La lucha entre el Estado y la Iglesia se había manifestado con la desamortización de las propiedades, de los inmuebles y con la transformación de la imagen urbana al derrumbarse iglesias y conventos, suprimirse nichos y capillas, vender y fraccionar huertas, ranchos y haciendas. Estos hechos significaban una muestra del poder secularizado de una sociedad civil en crecimiento, que buscaba borrar la imagen de la ciudad como expresión del poder y el control de la Iglesia.

Es decir, se permitió que espacios dedicados al culto religioso se destinaran y sirvieran como albergues para las instituciones que representaban al poder secularizado. "Por esta razón, los edificios, las calles, plazas, calzadas, jardines y paseos se fueron convirtiendo en espacios 'ganados' a la iglesia por el sector público, restándole con ello poder político”. ${ }^{\text {I4 }}$

\section{Espacio sagrado versus espacio público}

El 27 de enero de I857 el secretario del ayuntamiento recibió la respuesta del cabildo catedralicio. Ésta se centraba en contestar a las dos propuestas. Con respecto a la siembra de árboles se establecía que, de acuerdo con las leyes de la Iglesia, nada profano se podría hacer en los cementerios de los templos, pues el "atrio era un lugar sagrado, $[\ldots]$ consagrado de una manera solemne por la bendición Episcopal o Sacerdotal, para servir a la inhumación de los cadáveres, al reposo de los muertos, a la oración de los vivos y es como la antesala de la casa del Señor" Is La religiosidad del lugar estaba señalada por las cruces colocadas en los ángulos del atrio, "centinelas del templo que están diciendo con una elocuencia muda pero grave que se entra a un lugar sagrado; que el respeto y veneración del Santuario comienza desde allí, y que por lo mismo los fieles deben pisar con un temor santo el atrio del Señor". ${ }^{16}$

I4. María Estela Eguiarte, "Espacios públicos en la ciudad de México: paseos, plazas y jardines, I86I-I877", Historias. Revista de la Dirección de Estudios Históricos del Instituto Nacional de Antropología e Historia, México, enero-marzo, 1986, p. 93.

I5. AHGDF, Arboledas, I857, op. cit.

I6. Idem. 
Las autoridades eclesiásticas se negaron a la realización de las obras fundamentando que el atrio era un espacio consagrado, que no podía profanarse y convertirse en un paseo público. “QQué papel harán esas grandes cruces colocadas en los ángulos del atrio en medio de la alegría mundana de un paseo?” ${ }^{77}$ Sin embargo, estas consideraciones no querían reconocer el uso cotidiano que la colectividad de la ciudad le había dado a este espacio ¿ $\mathrm{O}$ es que acaso las autoridades eclesiásticas nunca vieron las luces de los hachones, no oyeron los gritos de los vendedores, las canciones de los pasteleros, las risas, los juegos; no sentían la presencia de una diversidad de gente que, después de misa por las mañanas o en las noches de luna, recorría este espacio? ¡Claro que lo sabían!, y así lo reconocen al señalar que la Iglesia había obrado en esto como había podido, colocando "unas cadenas, que no son un simple arbitrio, sino las señales que marcan un lugar sagrado y de oración, ha colocado unas cruces; tiene pagados dos vigilantes, y no abandona el pensamiento de cercar todo el atrio cuando sus facultades se lo permitan". ${ }^{18}$ Es decir, que no contaba con recursos y no podía autorizar el sembrar árboles ni contribuir con una aportación monetaria. Sutilmente hace saber que la falta de presupuesto, para satisfacer sus más urgentes necesidades, era consecuencia de los constantes préstamos que le había obligado a otorgar al gobierno. La falta de medios para proteger este espacio sagrado, donde descansaban las cenizas de los muertos, había impedido que se realizaran las obras de enrejado propuestas desde la época de Revillagigedo.

La falta de elementos, que definieran, separaran y protegieran a este espacio, había permitido que la comunidad lo usara y lo convirtiera en un paseo público.

El ayuntamiento contestó la misiva aclarando que de ninguna manera se pretendía atentar contra las inmunidades de la Iglesia. Sólo se proponía el mejoramiento del paseo y se solicitaba su cooperación porque se le consideraba "penetrada de los sentimientos patrióticos [...] especialmente cuando se trata de la belleza de un lugar que con árboles o sin ellos, siempre ha sido el recreo, no solo de los niños sino de las familias de esta ciudad". ${ }^{19}$ Aclarando que de ninguna manera los árboles afectarían la construcción ni la belleza del edificio, insistiendo en la concesión del permiso porque ese "lugar ha sido respetado por la culta población de México y escogido solo para un recreo inocente autorizado

I7. Idem.
I8. Idem.
I9. Idem. 
por el transcurso de muchos años y vigilado por las autoridades, con tanta o mayor eficacia que cualquier otro de los demás lugares públicos". ${ }^{20}$

Esta correspondencia deja en claro que el Paseo de las Cadenas fue producto de las necesidades de esparcimiento de los habitantes de la ciudad. Este espacio residual entre lo público y lo privado adquirió una actividad momentánea, versátil, gratuita, donde se establecían relaciones de sociabilidad.

El 5 de febrero de I857 fue promulgada la Constitución, la cual, en su artículo $3^{\circ}$ establecía la libertad de enseñanza, el $5^{\circ}$ se manifestaba contrario a los votos monásticos, el $7^{\circ}$ declaraba la libertad de imprenta, el $\mathrm{I} 3^{\circ}$ se refería a la supresión de fueros, el $27^{\circ}$ señalaba la prohibición para la iglesia de poseer o administrar bienes raíces y el $15^{\circ}$ establecía la libertad de cultos. La Constitución se tomó como una declaración de guerra, tanto los conservadores como el clero se apresuraron para iniciar un nuevo levantamiento que impidiera poner en práctica los principios constitucionales. La ciudad hervía, el presidente Ignacio Comonfort mostraba una actitud vacilante, los habitantes sentían que de un momento a otro se romperían las hostilidades.

La tensión entre la Iglesia y el gobierno aumentaba día con día. En apoyo a la Iglesia se hizo sentir la voz del Vaticano. El papa Pío IX ya había manifestado en diciembre de 1856 un voto de censura a la política reformista que se estaba aplicando en México, concretamente a las leyes Juárez y Lerdo. Su negativa a aceptar las propuestas constitucionales fueron constantemente sostenidas en sus alocuciones y encíclicas.

Ante esta situación, el I7 de febrero de I857 el deán de la catedral utilizando su más alta diplomacia política, para no demostrar su furia interna, contestó por última vez al ayuntamiento. Si en la primera misiva se había defendido el sentido religioso del espacio del Paseo de las Cadenas, en ésta se arremetía en contra del poder político que pudiera utilizar el ayuntamiento para apoderarse de ese sitio, pues consideraba que el simple hecho de sembrar unos árboles se podría convertir en la privatización de ese espacio religioso, pues "Vuestra señoría conoce bien que muchas cosas suceden contra la intención del que las obra”. ${ }^{2 \mathrm{I}}$

Entre líneas se puede leer que si bien las intenciones del ayuntamiento eran buenas, la Iglesia no sabía cuáles serían las del gobierno del Distrito o del gobierno federal. Su desconfianza estaba fundamentada en el hecho de que fungía 
como gobernador del Distrito Juan José Báez, enemigo declarado de la Iglesia, a quien consideraba como una institución usurera y de opresión.

El cabildo metropolitano sostenía que:

No se oponía a la mejora material porque le falten ideas de buen gusto y carezca de sentimientos patrióticos para contribuir a las mejoras materiales que se imaginen y realicen en esta hermosa ciudad; no se oponía porque fuera indiferente al bienestar, a la comodidad y a la salud de sus habitantes. Se oponía porque tenía principios que respetar y leyes que obedecer que no armonizaban con el proyecto. ${ }^{22}$

Para las autoridades eclesiásticas el hecho de permitir la siembra de árboles no sólo autorizaba la profanación de un lugar sagrado sino que se le otorgaba al ayuntamiento los medios para reconocerlo como un paseo público y por lo tanto podría exigir que quedara bajo su control.

¿Cree Vuestra señoría que la bendición que ha consagrado ese atrio tiene alguna relación, alguna armonía con el proyecto de un paseo público? [...] Por todos estos motivos a los cuales pueden agregarse otros muchos, espera este Cabildo que el Excelentísimo Ayuntamiento desista del proyecto, y suplicamos a Vuestra Señoría como a su Presidente le haga presente nuestras observaciones, por las cuáles verá que es del todo imposible prestemos nuestro consentimiento. Sírvase Vuestra Señoría admitir las protesta de nuestra consideración y aprecio. Dios Guarde a Vuestra Señoría muchos años. ${ }^{23}$

Esta carta llegó justo a tiempo para ser archivada. El ayuntamiento ya no tendría tiempo de responderla. La política vacilante de Comonfort cedía ante las presiones de los conservadores. Unos meses después, se promulgaba el plan de Tacubaya y el país entraba a la llamada guerra de Reforma o de los tres años.

La cotidianidad de los habitantes de la ciudad fue trastocada pero a pesar de ello tanto la Plaza como el Paseo de las Cadenas continuaban siendo el lugar de esparcimiento de una ciudad dividida, enfrentada, rota, encarnecida por los hechos entre liberales y conservadores. A pesar de los sucesos, entre rumores, temores y esperanzas, la ciudad de México mantenía sus formas acostumbradas. En el mesón del moro de Venecia, situado en la calle de Tlapaleros 


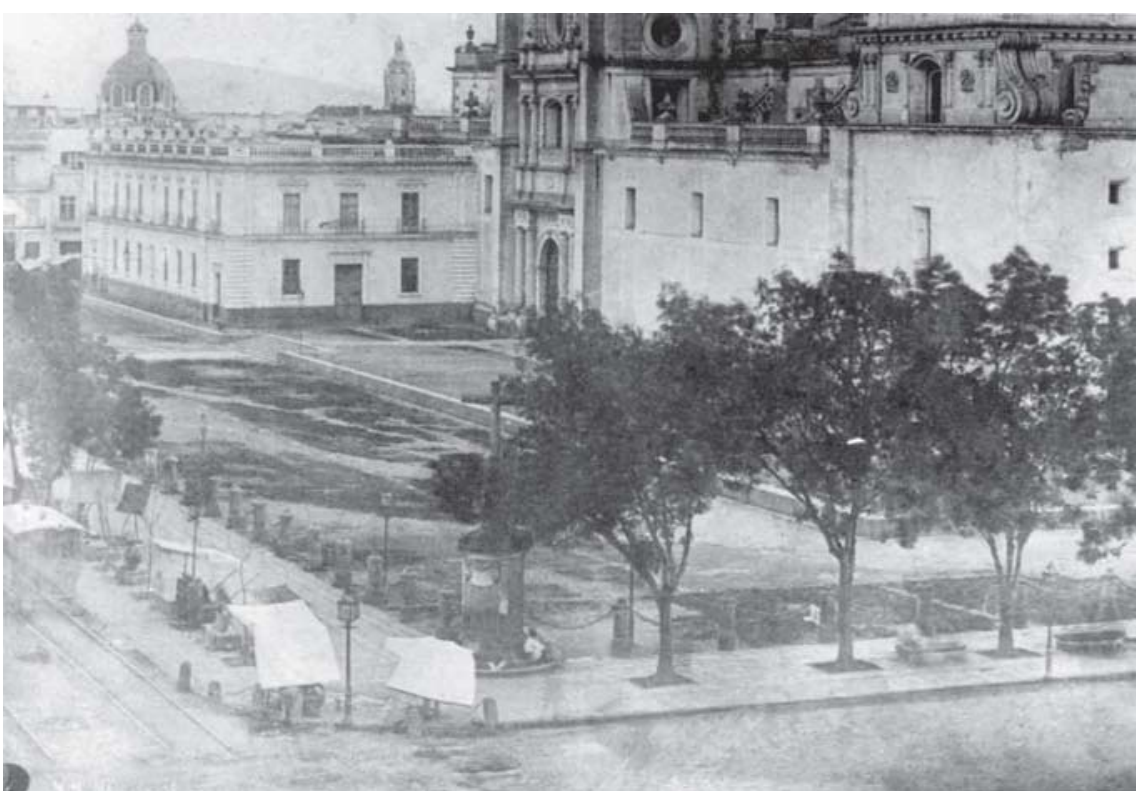

5. Fotografía del Paseo de las Cadenas, $c a$. 186r. Imagen de la Fototeca de la Coordinación Nacional de Monumentos Históricos, Instituto Nacional de Antropología e Historia, INAH 456-92. Reproducción autorizada por el Instituto Nacional de Antropología e Historia.

núm. I8, se seguía sirviendo el almuerzo a dos reales. El nuevo hotel Iturbide se levantaba majestuoso en la calle de San Francisco, los paseos seguían siendo La Alameda, La Viga, el de Bucareli y el Paseo de las Cadenas. Sin embargo, en éste se notaban los estragos por el abandono y el descuido, el follaje de los árboles había crecido, algunos faroles estaban rotos y no habían sido reparados, el piso se llenó de basura y la inseguridad se apropió de este espacio; por su parte, el cabildo catedralicio levantó las cadenas para impedir el paso. La rutina colectiva fue cambiando y ante los gustos impuestos por la aristocracia del imperio de Maximiliano, el paseo fue perdiendo el derecho de lo público que le había otorgado, en otros tiempos, la sociedad (fig. 3). Las noches de luna se empezaron a disfrutar en otros espacios más limpios y seguros.

El Paseo se fue diluyendo en el inmenso mar de los tiempos, en i88I el ayuntamiento - por iniciativa del encargado del ramo de Paseos, el señor Eugenio Barreiro-, propuso quitar las cadenas y extender la plaza hacia el atrio plantado de jardines con la intención de que estuvieran limpios y bien cuidados. En I883 
el cabildo de la catedral inició, bajo la dirección del arquitecto Juan Cardona, el retiro de los postes con las cadenas y la colocación del enrejado, obra que se concluyó en 1887.

Este cambio obedeció a una nueva conceptualización urbana de los grupos en el poder que buscaban redefinir los espacios públicos, privatizándolos para utilizarlos como un producto de los intereses del mercado, de la obsesión por la competitividad y sobre todo de la fuerza económica, que dentro de la organización urbana fue adquiriendo la iniciativa privada y perdiendo la iniciativa pública.

En los años del porfiriato las plazas, los paseos, los espacios intermedios, banquetas y calles ceden a los intereses privados. Circos, teatros, juegos mecánicos, transportes y vehículos se apoderan de los espacios públicos que van perdiendo su identificación como lugares cotidianos de mezclas e intercambios. El espacio público es el que paga la factura de una nueva organización urbana capitalista basada en la disolución, fragmentación y privatización. La ciudad ve condenar y convertirse a sus espacios públicos en zonas segregadas y en áreas fragmentadas; han dejado de ser lugares significativos, heterogéneos y de encuentro cotidiano. ${ }^{24}$

La historia del Paseo de las Cadenas nos permite conocer que durante la primera mitad del siglo xix, el espacio público se concebía como un elemento sujeto a la administración pública que fungía como propietaria poseedora del dominio sobre el suelo y, por lo tanto, podía garantizar la accesibilidad de todos y su utilización. En la segunda mitad del siglo xIx el espacio público reflejó la separación entre la propiedad privada y la propiedad pública, entre los intereses políticos públicos y los privados.

El Paseo de las Cadenas fue durante mucho tiempo una imagen de la ciudad que permitía el uso colectivo de los espacios públicos. Fue en su momento el ejemplo de un espacio donde se vincula lo público y lo religioso, pero también, la consecuencia de su ruptura y su distanciamiento. Es una marca en la historia de la ciudad, parte de la memoria urbana cuyo estudio nos permite identificarnos con su pasado y entender el presente. $\$$

24. Jordi Borja y Zaida Muxí, El espacio público: ciudad y ciudadanía, Barcelona, Diputació Barcelona, Electa, 2003, p. 3I. 